\title{
Power System Oscillation Damping Using New Facts Device
}

\author{
D. Narasimha Rao ${ }^{1}$, V. Saritha ${ }^{2}$ \\ ${ }^{1}$ Department of Electrical and Electronics, KL University, \\ ${ }^{2}$ Department of Electronics and Communication, VR Siddhartha Engineering College \\ Email: narasimharao@kluniversity.in, sarithagreen@gmail.Com
}

\begin{tabular}{l} 
Article Info \\
\hline Article history: \\
Received Oct 25, 2014 \\
Revised Dec 16, 2014 \\
Accepted Jan 6, 2015 \\
\hline
\end{tabular}

Keyword:

Current injection model

Damping Controller

DPFC

FACTS Device

Power Oscillation Damping

\begin{abstract}
This paper presents about improving stability of the system which can be possible with new FACTS device with more convenient. FACTS devices come under the influence of power electronics equipment. Distributed Power Flow Controller is a FACTS device used for damping low frequency oscillation with new controlling approach. It is valid for a wide range of the operating condition. In this work explain the basic model and its steady state operation, mathematical analysis injection of current control model of the DPFC. Using damping controller used in DPFC facts device as input to implement the task of power oscillation damping. Here this work had a brief study on damping, terminal voltage and excitation voltage at different load conditions, simulation results demonstrate damping low frequency oscillation at nominal, light and heavy loading conditions.
\end{abstract}

Copyright (C) 2015 Institute of Advanced Engineering and Science. All rights reserved.

\section{Corresponding Author:}

D. Narasimha Rao,

Department of Electrical and Electronics, K L University, India

Email: narasimharao@kluniversity.in

\section{INTRODUCTION}

Because of rapid increasing in load demand and rigid limitation of power generation causes the power system to be operated near to its stability limits and power system which are interconnected leads to rise to low frequency oscillation in the range of $0.5 \mathrm{~Hz}$ to $4 \mathrm{~Hz}$ [1]. Initial days PSS are used which are successful to control damping to some extent but it is very hard to damp the oscillation during large disturbance [1]. Utilising of FACTS Device are addressed to: increasing for its effective, to improve power system transmission capability, to improve first swing margin and to actively damp oscillation, also to help to stabilize weakly coupled system in the event of critical faults [2]. Initially FACTS Devices like SVC, TCSC, STATCOM, and TCPS are used but for more comforts and considering more inputs from both ends, mode consideration can be done by using shunt-series combination FACTS that is UPFC [3]. Recent FACTS Device known as DPFC FACTS Device it is a powerful FACTS Device in FACTS Family it provide with low cont and good in performance compare to UPFC. This Device not uses a common DC link as in UPFC [4]. It has great potential for damping the oscillations in the system. The contribution of this work is a novel current injection model and dynamic simulation of DPFC for studying low frequency damping and incorporating in the transmission system model [1]. A new way deal for proper design of DPFC damping controller is work going on here in this paper. The Problem of damping controller design for DPFC is formulated as a task. In this paper PSO technique was used to control oscillations [1]. Various FACTS Devices belongs to first and second generations particularly SVC, STATCON, SSSC, UPFC, IPFC are being used in literature in order to damp of the oscillation in power system. The main interesting work in this paper is using DPFC facts device with proposed current injection model in a simple power system to damp out the oscillation in different load cases [1]. Cost point of view also in place of UPFC the new device DPFC used [6]. 
A DPFC FACTS Device is a combination of shunt and series converter without a common DC link to exchange power between shunt and series converter. Shunt converter absorbs the power in one frequency and generating power in other frequency [6]. DPFC has three controllers central controllers which generated reference signals reference current and reference voltage given input to all the shunt and series controllers [5]. Each series controllers have its own series control through the line it need the line current, capacitor voltage and line voltages as input. A shunt controller has three phase converter connected back to back with single phase converter, three phase shunt converter takes power from the source and based on conditions series converter on controller inject a current in third harmonic frequency [5]. In series controller used to inject required compensated voltage in line.

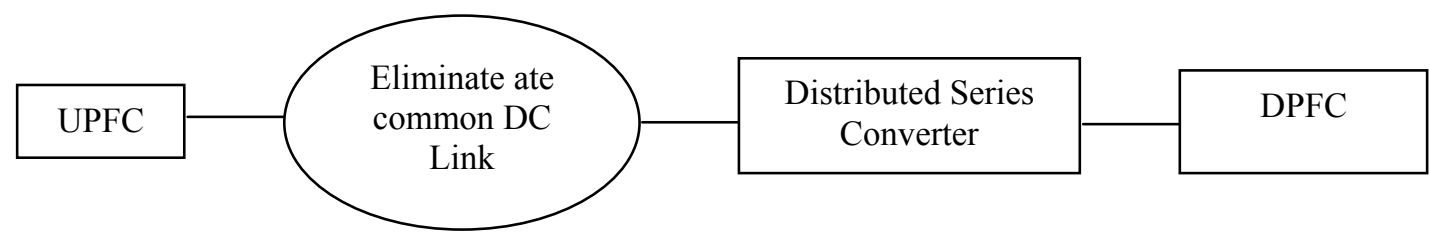

Figure 1. Basic formation of DPFC from UPFC

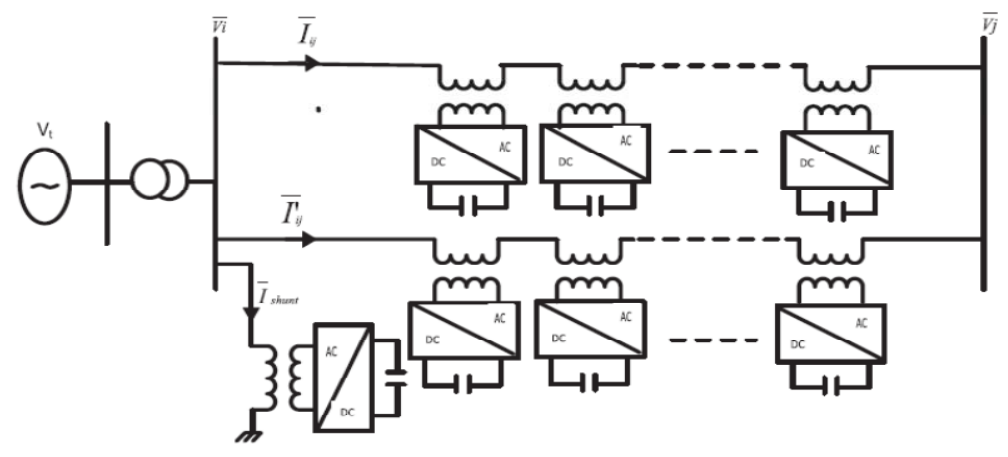

Figure 2. Power System model contain DPFC Model

\section{NEED OF CURRENT INJECTION MODEL}

In this study proposing current injection model for DPFC to study about low frequency oscillation. The idea of the current injection model is to use the current source which is connected as shunt instead of series voltage sources. The test power system this work consists two parallel lines and series converters are distributed over the lines

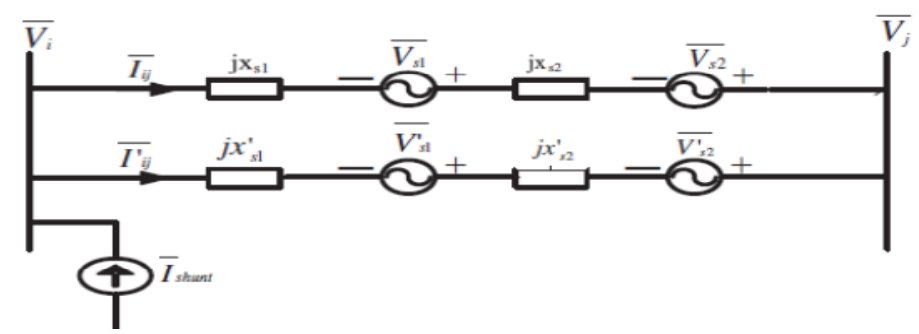

Figure 3. Electrical System in DPFC converts of case study transformation system

In the above figure all series converters are represent as voltage sources, as here we using a concept of current injection sources. Figure 4 having all the shunt and series converters representing as series and shunt current sources. 


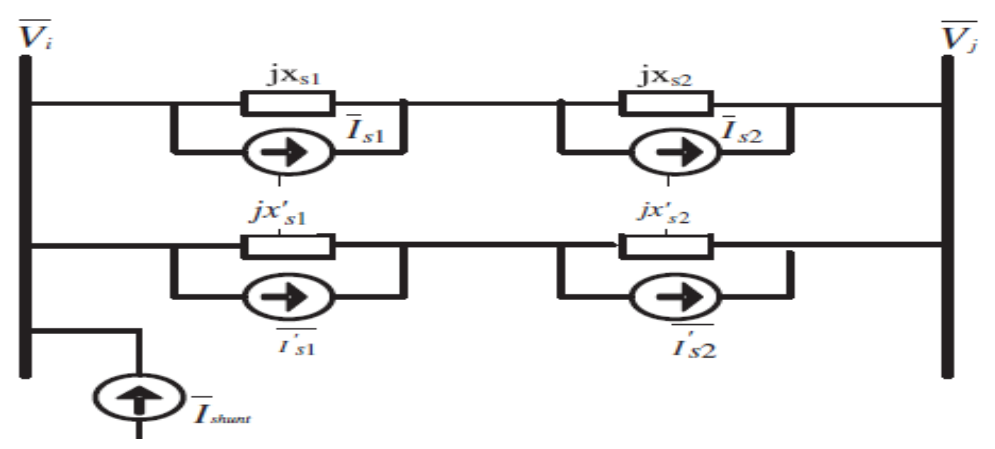

Figure 4. Represent of series voltage sources by current sources

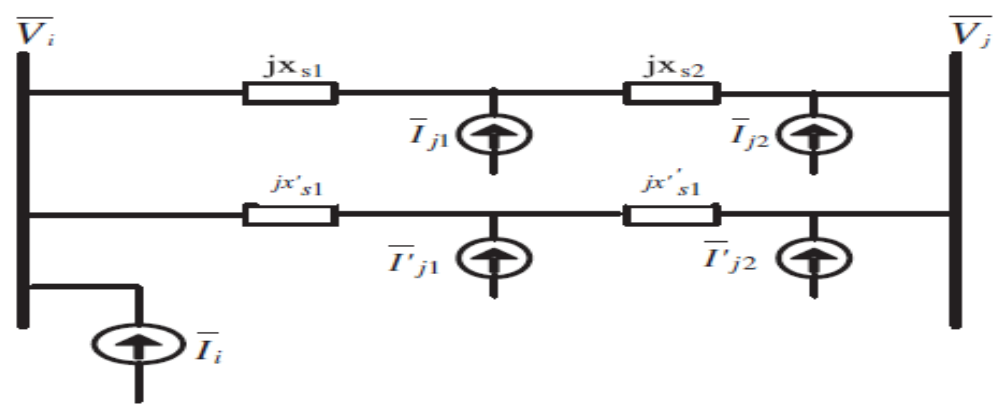

Figure 5. Current Injection model of DPFC

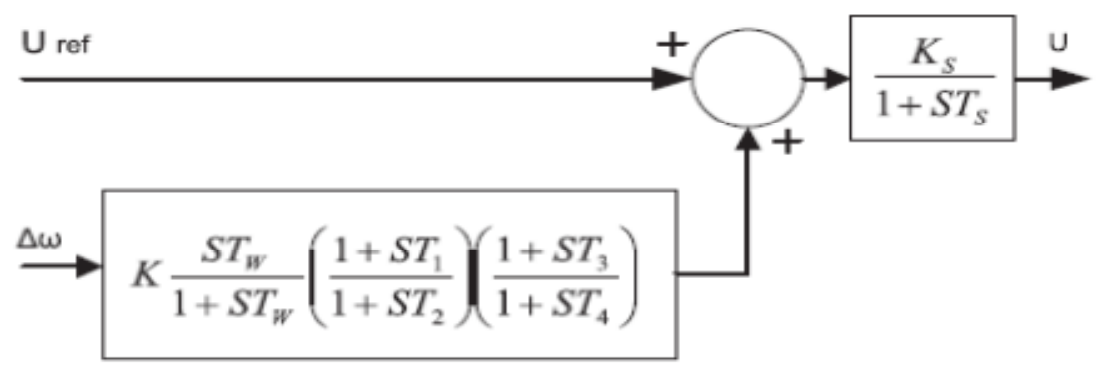

Figure 6. DPFC with lead -lag controller

Mathematical equation of shunt and series current based on current injection model:

$$
\mathrm{I}_{\mathrm{sh}}=\mathrm{I}_{1}+\mathrm{I}_{\mathrm{q}}
$$

The phase angle and magnitudes are of series converter are controllable. Here Vs1 = Vs2 = Vs3 = Vs4 = ${ }_{\mathrm{r}} \mathrm{V}_{\mathrm{i}} \mathrm{e}^{\mathrm{i} \lambda} . \mathrm{r}$ and $\lambda$ are the relative magnitude and phase angle with respective to $\mathrm{V}_{\mathrm{i}}$ respectively. And the expressions of series current source converters are

$$
\begin{aligned}
& \mathrm{I}_{\mathrm{s} 1}=\mathrm{V}_{\mathrm{s} 1} / \mathrm{j} \mathrm{X}_{\mathrm{s} 1}, \mathrm{Is} 2=\mathrm{V}_{\mathrm{s} 2} / \mathrm{j} \mathrm{X}_{\mathrm{s} 2}, \\
& \mathrm{Is}_{1}{ }_{1}=\mathrm{V}_{\mathrm{s} 1}^{1} / \mathrm{Jx}_{\mathrm{s} 1}^{1}, \\
& \mathrm{I}_{\mathrm{s} 2}^{1}=\mathrm{V}_{\mathrm{s} 2}^{1} / \mathrm{jX}_{\mathrm{s} 2}^{1},
\end{aligned}
$$

The active power supplied by the shunt current source can be shown as 


$$
\begin{aligned}
& P_{\text {shunt }}=R_{e}\left[V_{i}\left(-I_{\text {shunt }}\right)\right]=-V_{i} I_{1} \\
& P_{\text {shunt }}=P_{\text {series }}=P_{s 1}+P_{s 2}+P^{\prime}{ }_{s 1}+P^{\prime}{ }_{s 2}
\end{aligned}
$$

Current injection model of DPFC obtained as

$$
\begin{aligned}
& I_{\mathrm{i}}=I_{\text {shunt }}-I_{\mathrm{s} 1}-\mathrm{I}_{\mathrm{s} 1}^{1} \\
& \mathrm{I}_{\mathrm{j} 1}=\mathrm{I}_{\mathrm{s} 1}-\mathrm{I}_{\mathrm{s} 2} \\
& \mathrm{I}_{\mathrm{j} 2}=\mathrm{I}_{\mathrm{s} 2} \\
& \mathrm{I}_{\mathrm{j} 1}^{1}=\mathrm{I}_{\mathrm{s} 1}^{1}-\mathrm{I}_{\mathrm{s} 2}^{1} \\
& \mathrm{I}_{\mathrm{j} 2}^{1}=\mathrm{I}_{\mathrm{s} 2}^{1}
\end{aligned}
$$

From Equation 7 to 11 gives the current injection model parameter follow as

$$
\begin{aligned}
& \mathrm{I}_{\mathrm{i}}\left\{2\left(\mathrm{~b}_{\mathrm{s} 1}+\mathrm{b}_{\mathrm{s} 2}\right)\left[-\mathrm{rV}_{\mathrm{j}} \sin \left(\theta_{\mathrm{i}}-\theta_{\mathrm{j}}+\lambda\right)+\mathrm{rV}_{\mathrm{i}} \sin (\lambda)\right]+2\left(\mathrm{~b}_{\mathrm{s} 1}^{1}+\mathrm{b}_{\mathrm{s} 2}\right)\left(-\mathrm{rV} \mathrm{V}_{\mathrm{j}} \sin \left(\theta_{\mathrm{i}}-\theta_{\mathrm{j}}\right)+\right.\right. \\
& \left.\left.\mathrm{rV}_{\mathrm{i}} \sin (\lambda)\right)+\mathrm{jI}_{\mathrm{q}}\right\} \mathrm{e}^{\mathrm{j} \theta \mathrm{i}}+\mathrm{jb}_{\mathrm{s} 1} \mathrm{rV}_{\mathrm{i}} \mathrm{e}^{\mathrm{j}} \\
& \mathrm{I}_{\mathrm{j} 1}=-\mathrm{j} \mathrm{b}_{\mathrm{s} 1} r \mathrm{~V}_{\mathrm{i}} \mathrm{e}^{\mathrm{i} \lambda}+\mathrm{j} \mathrm{b}_{\mathrm{s} 2} \mathrm{rV} \mathrm{V}_{\mathrm{i}} \mathrm{e}^{\mathrm{i} \lambda} \\
& \mathrm{I}_{\mathrm{j} 2}=-\mathrm{j} \mathrm{b}_{\mathrm{s} 2} \mathrm{rV} \mathrm{i}_{\mathrm{i}}^{\mathrm{i} \lambda} \\
& \mathrm{I}_{\mathrm{j} 1}=-\mathrm{jb}{ }_{\mathrm{s} 1}^{1} \mathrm{rV}_{\mathrm{i}} \mathrm{e}^{\mathrm{i} \lambda}+\mathrm{jb}^{1}{ }_{\mathrm{s} 2} \mathrm{rV}_{\mathrm{i}} \mathrm{e}^{\mathrm{i} \lambda} \\
& \mathrm{I}_{\mathrm{j} 2}=-\mathrm{jb}{ }_{\mathrm{s} 2}^{1} \mathrm{rV}_{\mathrm{i}} \mathrm{e}^{\mathrm{i} \lambda}
\end{aligned}
$$

\section{SIMULATION AND RESULTS}

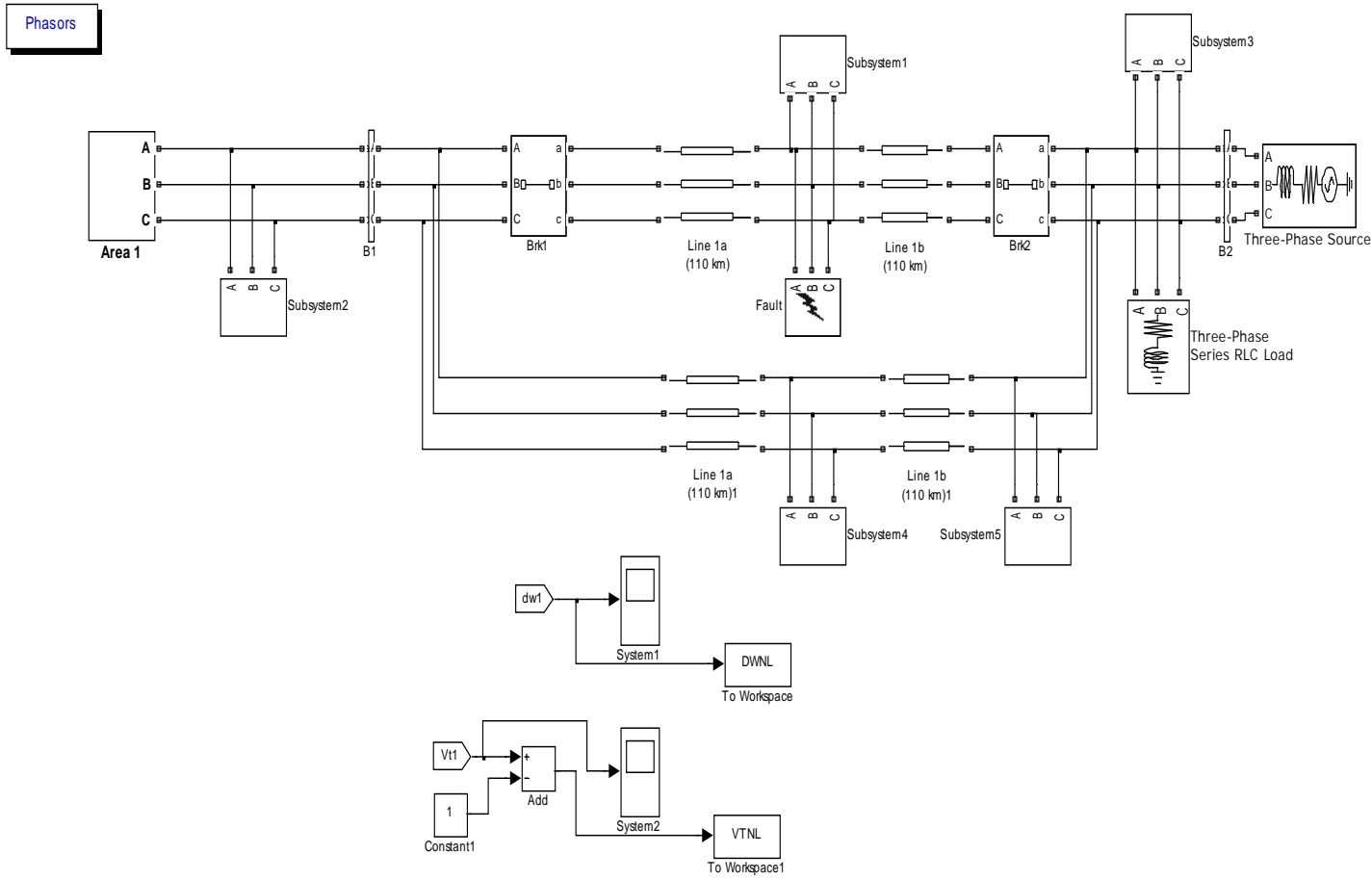

Figure 7. Single Machine Infinite bus with DPFC with MATLAB/Simulink 


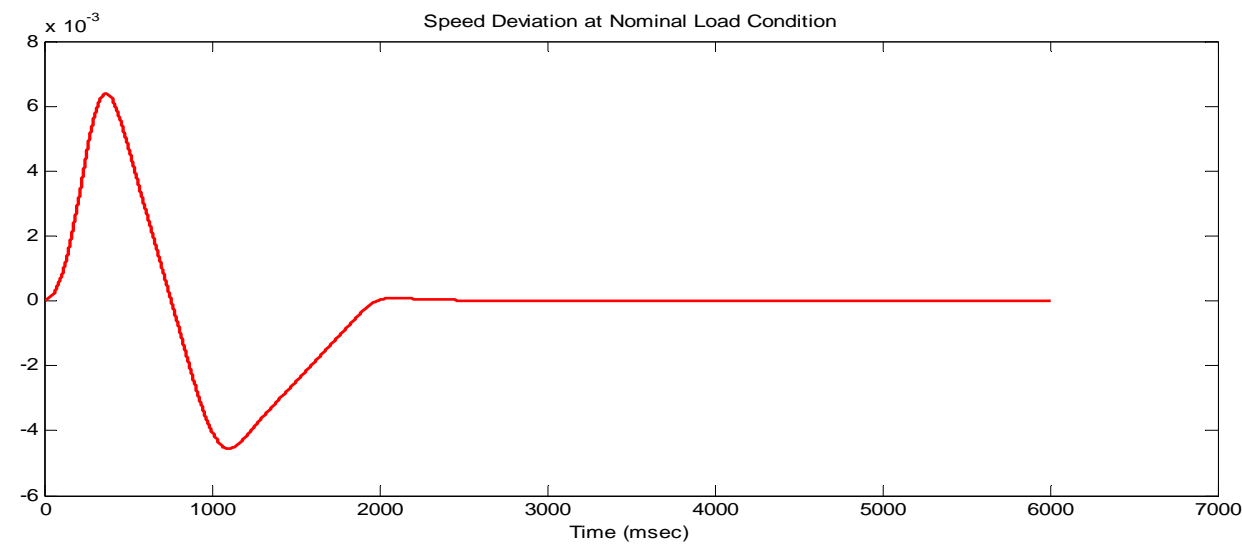

Figure 8. Dynamic response of speed deviation at normal load conditions

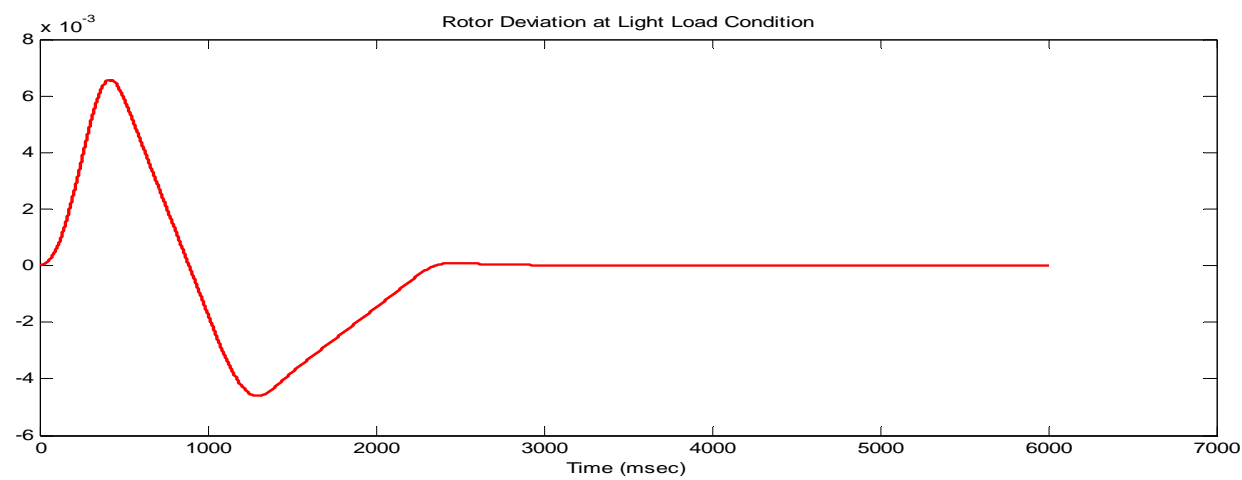

Figure 9. Dynamic response of speed deviation at light load conditions

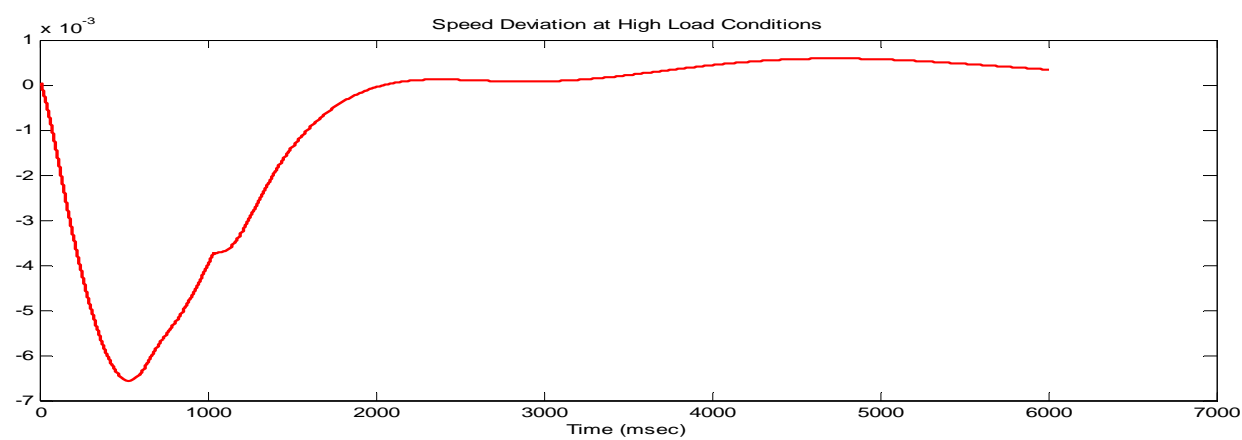

Figure 10. Dynamic response of speed deviation at heavy load conditions 


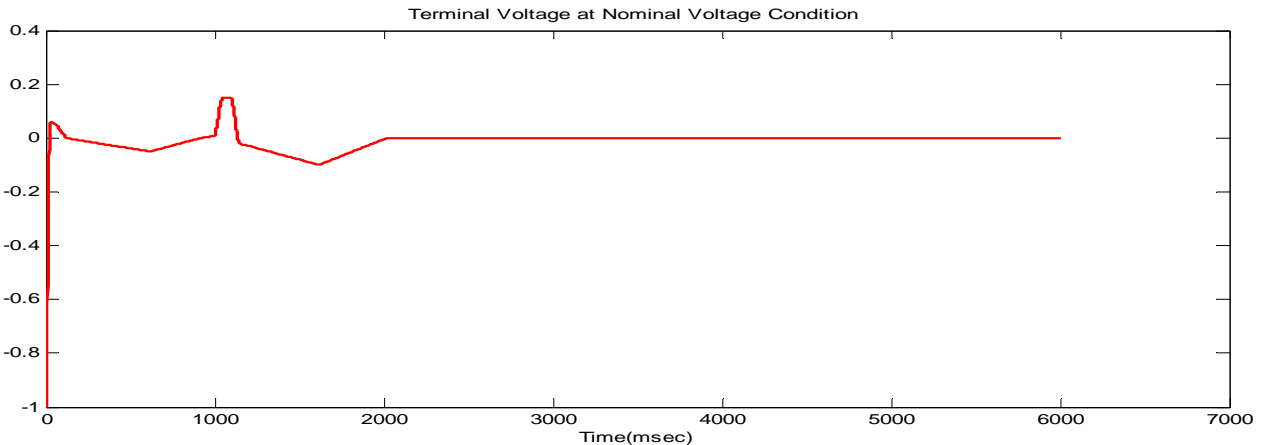

Figure 11. Dynamic response of terminal voltage deviation at nominal load conditions

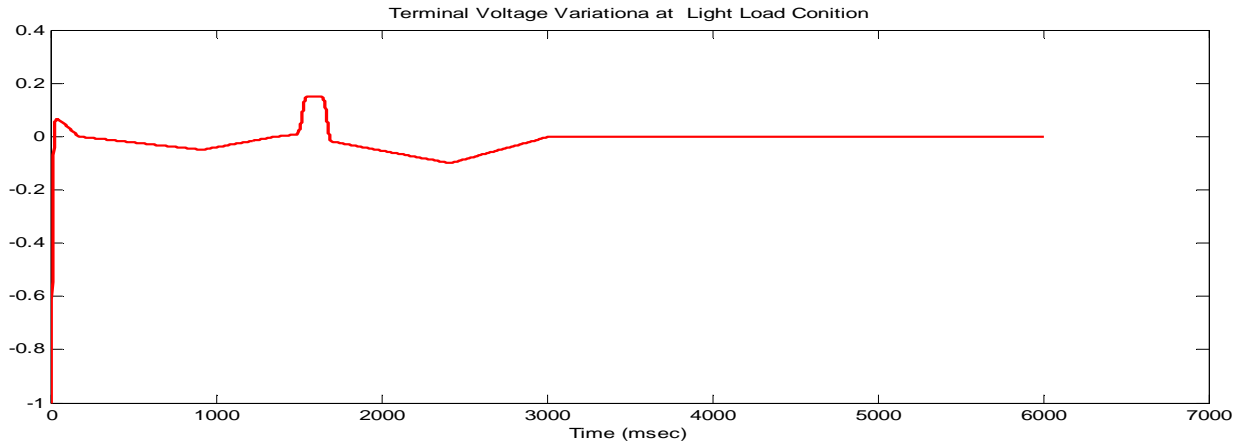

Figure 12. Dynamic response of terminal voltage deviation at light load conditions

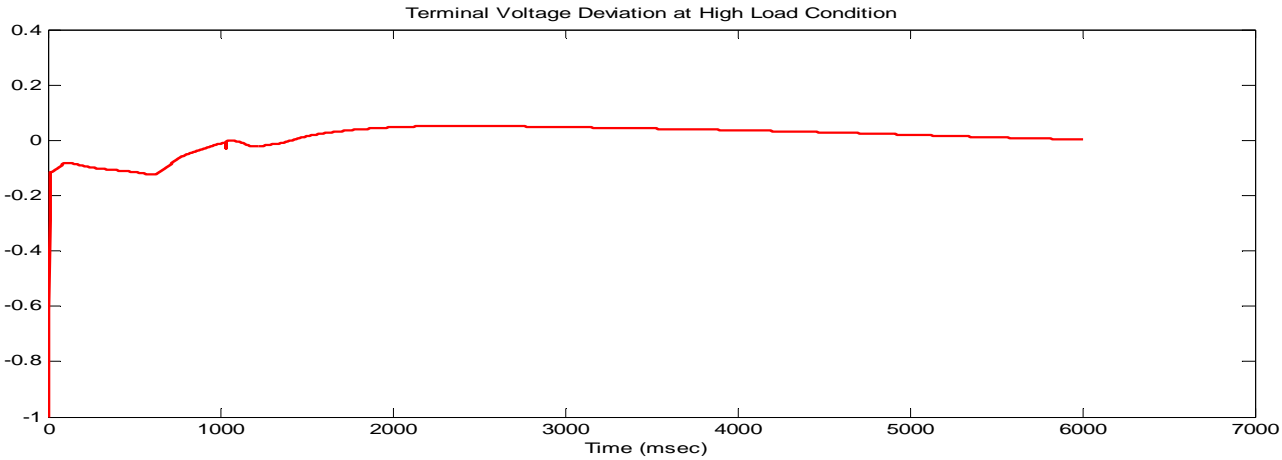

Figure 13. Dynamic response of terminal voltage deviation at heavy load conditions

\section{COMPARSION RESULTS AT DIFFERENT LOAD CASES}

By observing results from Figure 8 to 13 the time taken by the rotor is less to reach its steady state value if any changes occurs in the loading condition and it was observed that settling time of rotor deviation is less at heavy and nominal load condition compare to light load condition similarly time taken for stabilizing the terminal voltages is also less time for nominal load condition compare to light load condition.

Table 1. Comparison results at different load case

\begin{tabular}{|c|c|c|c|}
\hline $\begin{array}{l}\text { Load conditions } \\
\text { Parameters }\end{array}$ & Light load conditions & Normal Load Conditions & Heavy Load Conditions \\
\hline Speed Deviation & $2400 \mathrm{msec}$ & $2000 \mathrm{msec}$ & $2000 \mathrm{msec}$ \\
\hline $\begin{array}{c}\text { Terminal Voltage } \\
\text { Deviation }\end{array}$ & $3000 \mathrm{msec}$ & $2000 \mathrm{msec}$ & $1800 \mathrm{msec}$ \\
\hline
\end{tabular}




\section{CONCLUSION}

In this work, the new FACTS Device DPFC can regulate the line reactive and active power flow to provide enough damping the system oscillation using controller of lead - lag compensation and we gone through in three different load condition using lead lag controller technique and observing the terminal voltage, speed deviation. Further we can observe change of generated output and excitation voltage, and if applying neural or genetic algorithms can get better performance.

\section{REFERENCES}

[1] Amin Safari, Behrouz Soulat, Ali Ajami. Modelling and unified tuning of distributed power flow controller for damping of power system oscillations. Ain Shams Engineering Jounal. feb 2013

[2] James F. Gronquist, William A. Sethares, Frenado L. Alvarado Robert H. Lasseter. Power Oscillation damping control strategies for FACTS devices using local measurable quantities. IEEE transaction on Power Systems. Vol. 10, No. 3, August 1995: 1598 - 1605.

[3] Hingorani JNG, Gyugi L. Understanding FACTS: Concepts and technology of Flexible AC transmission system. Newyork: IEEE Press 2000.

[4] Ahmed jamshidi, S. Masoud Barakati, M. Moradi Ghahderijani. Impact of distributed power flow controller to improve power quality based on synchronous reference frame method. IACSIT International Journal of Engineering \& Technology. Vol. 4, No. 5, October 2012, 581-585.

[5] O. Sushma, Dr. K.S.R. Anjaneyulu. Modelling of Distributed Power Flow Controller (DPFC) Using Matlab/Simulation. International Journal of Engineering Research \& Technology (IJERT). ISSN: 2278 -0181, Vol. 2, Issue 1, January 2013, 1-7.

[6] Sarimalla Pedakotaiah and Santosh. Simulation of Distributed power flow controller (DPFC). International Journal of Engineering Science. ISBN: 2319 -6483, ISSN: 2278 - 4721, Vol. 2, Issue 1, January 2013, 25-32. 